Arteterapia. Papeles de arteterapia y educación para inclusión social ISSN-e 1988-8309

http://dx.doi.org/10.5209/ARTE.59487

\title{
Prácticas artísticas contemporáneas y construcción de conocimiento en la mediación en museos con personas afectadas de Alzheimer
}

\author{
Marta García Cano ${ }^{1}$
}

Recibido: 10 de marzo de 2018 / Aceptado el 3 de julio de 2018

Resumen. La idea de que el museo pueda actuar como un agente social ante el territorio y sus habitantes atraviesa, cada vez más, las políticas y estrategias de la institución. Términos como mediador o artista/ educador, y el concepto que sostienen, activan modos de hacer y paradigmas pedagógicos en aras de la acción social. Desde esta perspectiva se presenta la experiencia llevada a cabo con un colectivo de personas con Alzheimer en el Centro de Arte de Alcobendas (Madrid), financiada por DKV Seguros. Los objetivos de esta propuesta pretenden comprobar la validez, y establecer las posibles aportaciones de una metodología basada en las prácticas artistas contemporáneas como formato pedagógico en la labor de mediación y acercamiento a colectivos desde la sala de arte. Se plantea igualmente entender dicha experiencia como producción de conocimiento, en sentido bidireccional, del museo al contexto de salud y a la sociedad, del contexto de salud y la comunidad, al museo. Del análisis de los resultados, realizado desde una metodología cualitativa, implícita en las propias prácticas artísticas, se evidencian resultados muy concretos para el colectivo. Por otra parte, se proyecta una mirada más global y se establecen unos criterios y preguntas de investigación, qué permiten reflexionar sobre la utilidad social de estas actuaciones, su eficiencia y sostenibilidad en la producción de conocimiento y en el objetivo de transformación.

Palabras clave: Alzheimer; prácticas artísticas contemporáneas; mediación en museos; producción de conocimiento.

\section{[en] Contemporary art practices and knowledge production into mediation in museums for People with Alzheimer}

\begin{abstract}
The Contemporary art museums acting like social agent before the territory and its inhabitants is becoming an emerging idea going through the strategies of the institution. Mediator and artist/educator and the new understanding for them encourage education team works strategies to social involvement. From this point of view, an experience with people with Alzheimer and their companions in Centro de Arte de Alcobendas (Madrid) funded by DKV Seguros is introduced. The aim designed for this proposal pretend to find out evidence about the validity and new possibilities of this methodology based on contemporary art practices in the context of museums education, especially regarding health collective. We also understand the experience as social knowledge production driving in two ways. From the museum to the collective and society and the opposite. The results have been analyzed throughout a qualitative research method (implicit in artist practices) and they have displayed specific therapeutic benefits. On the other hand, from a wider point of view, some judgement and research questions have been made in order to consider the utility, efficiency and sustainability of this practices and its influence in social transformation.
\end{abstract}

Keywords: Alzheimer; contemporary art practice; mediation; cultural production.

1 Universidad Complutense de Madrid. Departamento de didáctica de las lenguas, artes y Educación física martag02@ucm.es 
Sumario: 1. Contexto. 1.1. Centro de Arte Alcobendas.1.2. Asociación de Familiares de Enfermos de Alzheimer de Alcobendas y San Sebastián de los Reyes. 1.3. La exposición. 2. Consideraciones en torno al museo, la mediación y la transformación social. 2.1. El museo de arte contemporáneo como espacio para la construcción social. 2.2. La mediación. 2.2.1. Prácticas artísticas contemporáneas para la mediación. 3. Investigar. 4. Arte-Salud-Alzheimer y producción de conocimiento. 5. La propuesta. 5.1. La importancia de definir los conceptos. 5.1.1. Habitar. 5.1.2. Cotidiano. 5.1.3. La instalación como forma de habitar y producción cultural colectiva. 5.2 Metodología. 5.3. Objetivos. 5.4. Desarrollo y metodología específica de las sesiones. 5.4.1. Acción de presentación y situación en el espacio. 5.4.2. Las sesiones. 5.4.3. Análisis de lo sucedido 6. Conclusiones.7. Discusión 8. Referencias bibliográficas.

Cómo citar: García Cano, M. (2018). Prácticas artísticas contemporáneas y construcción de conocimiento en la mediación en museos con personas afectadas de Alzheimer, en Arteterapia. Papeles de arteterapia y educación para inclusión social 13, 2018, 33-52.

\section{Contexto}

Con motivo de la exposición La creación del paisaje contemporáneo. Colección DKV - colección Alcobendas, en el Centro de Arte de Alcobendas, DKV Seguros financia una serie de talleres destinados a colectivos o entidades relacionadas con la salud.

\section{El Centro de Arte de Alcobendas ${ }^{2}$}

Inaugurado en noviembre del 2010, el Centro se presenta como un espacio de referencia para las artes con vocación internacional y sede de una colección de fotografía contemporánea. Además, acoge exposiciones temporales de Arte Contemporáneo, tiene una programación estable de música, un servicio de mediateca y un equipo educativo cuya misión es hacer accesible el arte contemporáneo y establecer un diálogo participativo entre el Centro y, especialmente, el público de la zona norte de la Comunidad de Madrid, y convertirse así en punto de encuentro.

La programación abarca actividades para un público muy variado y mantiene una intensa relación con los centros educativos de la zona para los que realizan actividades específicas. Destaca el trabajo con los colegios de educación infantil. En este caso, ante la dificultad de estos para desplazarse, son los propios educadores los que se desplazan al colegio.

La propuesta de un proyecto relacionado con públicos dentro del ámbito de la salud se presenta como una oportunidad en la medida de que no siempre es una tarea fácil de abordar. La falta de financiación y personal dificulta acercamientos que, en ocasiones, son complicados, dada la situación familiar, social y de salud de muchos de estos públicos. Como parte del Ayuntamiento, los motivos que les mueven tienen que ver con su misión de gestionar para todos los ciudadanos desde una ciudad inteligente, solidaria y comprometida con la calidad de vida. Cuestiones que implican activar una cultura de participación con todo tipo de públicos y colaboración con otros agentes del ayuntamiento, entidades externas y expertas para lograr afianzar y

2 Aunque la idea de Centro de Arte y Museo difiere en algunos aspectos se ha decidido hablar de museos en general por entender que ambos son espacios de Arte Contemporáneo y en definitiva tienen una misión dentro de su contexto en la que convergen las cuestiones principales que aquí se tratan 
fidelizar nuevos públicos, desarrollar trabajo en bien de la comunidad y dar visibilidad al trabajo a través de los congresos, publicaciones etc.

\subsection{Asociación de Familiares de Enfermos de Alzheimer de Alcobendas y San Sebastián de los Reyes}

Se trata de una organización sin ánimo de lucro impulsada por los propios familiares, afectados y colaboradores voluntarios, que trabajan para mejorar la calidad de vida de los enfermos de Alzheimer y las personas que se ocupan de su cuidado.

Sus objetivos son: información, formación, asesoramiento y apoyo para familiares y personas próximas a los enfermos, acerca de todos los aspectos relacionados con la enfermedad y la atención al enfermo en las diferentes etapas.

Dentro de esa atención, uno de los objetivos es mantener la capacidad cognitiva y funcional de las personas afectadas para intentar frenar problemas de memoria, orientación y atención. Actualmente, dirigidos por la Psicóloga Estela García, trabajan dos veces por semana con dos grupos en diferentes fases de la enfermedad. De manera puntual hacen actividades de ocio, magia, conciertos, teatro etc. y actividades de musicoterapia en las que se incluye a las familias.

\subsection{La exposición}

Alicia Ventura, comisaria de exposiciones del Programa Arteria y directora del proyecto cuidArt en el Hospital Marina Salud de Denia, la describe de la siguiente manera en el catálogo de la exposición (2016 p. 4).

«La antigua distinción entre la ciudad y la naturaleza se quiebra hoy ante la presencia de un territorio discontinuamente urbanizado, de un paisaje intermitente que hibrida los usos urbanos con las preexistencias agrícolas. Los distintos trabajos presentes en la muestra registran esta nueva realidad, y conforman un nuevo atlas de los territorios de nuestra cotidianeidad, construyendo narraciones inéditas en torno a nuevos lugares y nuevas situaciones. En esta exposición, el fotógrafo retrata la posición del hombre ante la naturaleza en términos de actor y espectador. Muchos de los trabajos que la conforman analizan la intervención del hombre en el territorio, y retoman así, desde una perspectiva contemporánea y casi documental, la histórica tensión entre cultura y naturaleza. En otras obras, sin embargo, los recursos de la ficción se apoderan del espacio urbano y rural, recordándonos la condición necesariamente ambigua y construida del paisaje, a mitad de camino entre la naturaleza y el artificio.»

\section{Consideraciones en torno a la mediación en museos y la transformación social.}

\subsection{El museo de arte contemporáneo como espacio de construcción social.}

Según SEC los museos han de actuar como instituciones que escuchan, dialogan y responden a los problemas de la sociedad y se comprometen a actuar como elementos dinamizadores capaces de contribuir a su transformación (2015, p. 4). 
Para autores como Dodd y Sandell (Delgado 2016, p.146), las actuaciones de los museos en este sentido deben estar relacionadas con los siguientes objetivos: elevar la autoestima de los ciudadanos, reforzar y fortalecer las potencialidades, equilibrando las debilidades individuales y favoreciendo el control sobre la propia vida. Informar y propiciar el aprendizaje. Promover la creatividad. Ampliar el horizonte individual hacia nuevas formas de ver el mundo. Impulsar debates sobre temas polémicos y de interés. Desafiar los estereotipos. Enfrentar la intolerancia.

Más que nunca, museos, salas y centros de arte están en una continua revisión de su función dentro de la sociedad y del impacto que su labor puede tener. En sus intentos de acercamiento a otros públicos han establecido diferentes grados de conexión con el «afuera», en los que conviven diferentes enfoques y posicionamientos pedagógicos. Carmen Mörsch (2010) hace cuatro distinciones acerca de estos modelos que se resumen brevemente: 1) El autoritario. Se basa en comunicar contenidos. 2) El reproductivo. Actúa como puerta de acceso a un público consumidor de cultura, su intención pedagógica se visibiliza a través de actividades y talleres que reproducen el discurso, sin entrar en otro tipo de cuestiones. 3) El deconstructivo. Más político, permite el análisis crítico y se nutre de un equipo educativo que plantea en sus acciones cuestiones reflexivas sobre la propia institución y las acciones que esta produce. 4) El transformativo. Entiende el arte y la propia institución como vehículos de reflexión y creación de conocimiento social, político y cultural que le lleva a establecer colaboraciones y alianzas con otras instituciones, agrupaciones o colectivos.

Desde este último modelo es donde se establece el contacto con sectores vulnerables de la población y el museo se convierte en un espacio de encuentro, en zona de contacto según Clifford, (2012) o lugares entre-medias, donde se generan nuevas formas de cultura que implican entender la institución cultural como un espacio de transformación social. Aceptar este paradigma transformativo es entender el museo como un agente social en el que la exposición no es un fin en sí misma sino una «excusa» para que se generen relaciones productivas entre el dentro y el afuera: investigación, educación, conocimiento. Sitúa a sus públicos como participes, artífices y beneficiarios de propuestas compartidas, posibilitadoras de construcción de significado y oportunidades. Esta tarea requiere un esfuerzo y exige estrategias de acercamiento alejadas de las tradicionales, que muestren esa semejanza a otros agentes sociales en su utilidad. Por eso una de ellas es presentarse como un agente social mediador que ofrece propuestas de colaboración en las que todos tienen algo que ganar.

\subsection{La mediación en museos}

En este contexto surge también la necesidad de expandir la idea de la educación en museos y entenderla desde ese paradigma transformativo, acorde con la sociedad del conocimiento y las nuevas formas de producción de este. Por ello, cada vez aparece más el término mediación que, por su significado y procedencia de lo social, está relacionado con la existencia de conflicto, lo que significa aceptar que, la relación del museo y del arte contemporáneo con el afuera, presenta dificultades que requieren diálogo para poder relacionarse. No se trata sólo de salvar la distancia entre el público y el museo, entre el arte y el visitante, sino de establecer vínculos en los que exista implicación por ambas partes. 
Desde Pedagogías y redes instituyentes, los colectivos Transductores y Sinapsis hablan de la educación o mediación en museos como las políticas de programas, proyectos o iniciativas que una institución genera, como las subjetividades, y relaciones culturales que cruzan el museo y generan ideas y valores sobre la cultura, así como los dispositivos, artefactos, espacios y lugares que generan mediaciones o interacciones sociales con los grupos visitantes o con el territorio. Lo que significa entender el museo como un dispositivo pedagógico, y como tal, transformador.

En este agenciamiento se produce, en palabras de Deleuze y Guattari (2009), un aumento de dimensiones en una multiplicidad que cambia necesariamente de naturaleza, a medida que aumenta sus conexiones. Incluir estrategias de las prácticas artísticas como parte de la acción pedagógica y de la mediación, es una de ellas, permitiendo modelos más abiertos a la búsqueda y experimentación y no tanto a perseguir objetivos preestablecidos e inamovibles. Lo educativo pasa por desbordarse y adentrarse en territorios que atraviesan modos de hacer instalándose en lo pedagógico/artístico. La cuestión reside en proponer/crear situaciones donde emerjan nuevas relaciones con el arte y el museo, el adentro y el afuera, que ejerzan ese papel de agente social.

\subsubsection{Prácticas artísticas contemporáneas para la mediación}

Para Dewey (2008), el arte debería ser capaz de contribuir al fortalecimiento de las esferas ciudadanas y la participación de sujetos, formas y espacios diferentes. Desde el pragmatismo, el filósofo y pedagogo sostiene que es, a través de la experiencia y de la toma de conciencia de la misma, cuando se produce el conocimiento y por tanto, se produce una transformación. No en vano, el autor se presenta como referencia teórica para muchos artistas y teóricos del arte en lo que se ha dado en llamar Arte de Contexto, Arte y Participación, Arte Comunitario, Arte colaborativo, etc. Emplear la práctica artística de participación en la mediación y visibilizar dicha práctica permite, no sólo construir conocimiento de forma colectiva, nos introduce en la creatividad social a la par que ponen de manifiesto la subjetividad.

Arte colaborativo, arte de contexto o arte comunitario son términos dentro del arte que proponen diferentes modos de participación e implicación interesadas en provocar, cuanto menos, micro-transformaciones en el ámbito social y político y modos de relación alternativos, entendiendo alternativo no como al margen de, sino como existencia de otra posibilidad.

Si Bourriaud (2006) define el arte como ese lugar de producción de una sociabilidad específica: el arte es un estado de encuentro en unas determinadas condiciones, cabe preguntarse si el museo no lo es igualmente. El museo, como contexto, produce unas condiciones de sociabilidad que, al entrar en contacto con otros agentes, a través de la mediación, puede producir situaciones específicas para: de una parte, romper las barreras que el museo, como institución «per se», proyecta sobre públicos fuera del ámbito artístico y dificulta relaciones más permeables y enriquecedoras. Y por otro, establecer estrategias que permitan conexiones con diferentes realidades sociales. Por ejemplo, el encuentro con una asociación de Alzheimer, donde no solo se produce una experiencia de bienestar en la que se observan beneficios específicos, también se construyen modelos de relación entre la institución, las personas y la Asociación y, sobre todo, conocimiento permeable a las prácticas habituales del gru- 
po en su trabajo terapéutico, modificando el enfoque y el modo de hacer de algunas prácticas e implícitamente la relación entre el grupo y la propia terapeuta.

Si bien el eje vertebrador de esas prácticas reside en los modos de participación y esos modos están supeditados al grupo, colectivo, público, institución, con quien se trabaje, las estrategias del arte de participación y colaborativo podemos concretarlas en lo siguiente:

- Diálogo. Establecer acuerdos.

- Acción. Producir experiencias.

- Atención al proceso. Abierto y flexible.

- La búsqueda de posibilidades y no la persecución de objetivos.

- Estéticas de la participación/implicación.

- Modos de reproducción.

- La reflexión.

\section{Investigar}

Estas prácticas artísticas a las que podríamos denominar «tentativas» como las 1lamaría el pedagogo francés Deligny, refiriéndose a esos espacios educativos que funcionan mientras permiten a quienes habitan seguir aprendiendo, seguir respirando, seguir desplazándose, seguir tejiendo un mapa imprevisible de alianzas con otras tentativas, no están lejos de otras prácticas llevadas a cabo desde otras disciplinas de las ciencias sociales, como la sociología misma entre otras. Todas convergen en un mismo propósito: llevar a cabo transformaciones efectivas y consecuentemente aprendizajes, lo que significa, inevitablemente, investigar para que eso suceda, para aprender por qué sucede o no. Es aquí donde de forma natural el arte, cuando actúa en ese sentido, se agencia estrategias de la investigación-acción-participación (G. Cano, 2013 p.119).

Si valoramos las prácticas artísticas como metodologías de investigación, podrían estas elevar su estatus de validez en la construcción de la mejora social e incorporar a sus agentes como parte de cualquier equipo, cuyo objetivo sea trabajar en la realidad social para aportar mejoras y, en consecuencia, hacer de un equipo de mediación a través de prácticas artísticas un equipo de investigación en colaboración con asociaciones, organizaciones, diferentes colectivos, etc.

Reunidas todas estas visiones, la propuesta de análisis de estas experiencias se hace compleja, aunque esa complejidad no debe alejarnos de una realidad: si lo que se busca con estos proyectos es intervenir para mejorar, aportar, ofrecer posibilidades o conseguir unos objetivos educativos, terapéuticos, etc. es lógico que el resultado de esa intervención pueda ser evaluado, en la medida que ello significa conseguir recursos públicos que lo sigan apoyando. Esa evaluación obliga a establecer criterios de efectividad y reflexión que respondan las siguientes preguntas:

«¿qué encontramos al principio? ¿Qué tenemos al final? ¿Para quién es útil y desde qué perspectiva? ¿Es posible un cambio sostenible? ¿Han aflorado nuevas oportunidades? ¿Han sido valoradas? ¿Por quién? ¿Qué valoración tiene el proceso en el contexto que se produce la acción? ¿Qué conocimiento se produce?» (G. Cano, 2013 p. 131) 
La cuestión ahora es determinar los criterios que atraviesan esas preguntas cuando se usan como metodología en la mediación dentro del museo y desde qué perspectivas se pueden establecer estos, para obtener una visión que permita detectar con claridad cómo, actuaciones concretas, se proyectan a lo colectivo y a la sociedad en general.

1) Perspectiva relacional y política. Se trata de que el museo se adentre en el tejido social y pueda cuestionarse su función, sus acciones, sus relaciones para desarrollar proyectos que puedan incorporar nuevas formas de relación cultural en favor de un mayor conocimiento. Como afirma Parramón (2003), el éxito o logro de este tipo de prácticas pasa por entender el intercambio que se puede establecer entre los implicados, en el que todos pueden dar, pero también deben obtener. Desde aquí, la efectividad debe responder a criterios que atañen a la persona, al colectivo, a la institución y la significatividad de las acciones:

- Grado de colaboración entre colectivo e institución. Determina el interés por ambas partes.

- Deseo de continuidad y motivación.

- Grado de utilidad para las partes.

- Producción de conocimiento transferible.

- Capacidad de proponer modelos transferibles (prototipos).

2) Perspectiva Pedagógica. Sumar modos de hacer, es decir, formas de conocimiento, vinculados a la experiencia capaces de ejercer un papel transformador en nuestra visión de lo que nos rodea.

3) Perspectiva Terapéutica.

a. Beneficios relacionados con el bienestar y la salud:

- Experiencia de socialización positiva encaminada a reducir el aislamiento social.

- Oportunidades de adquirir nuevas habilidades.

- Experiencias relajantes, reducen el estrés.

- Aumento de emociones positivas.

- Aumento de la autoestima.

- Incremento de las oportunidades de creatividad inspiración y construcción de sentido.

- Distracción positiva del contexto clínico.

- Aumento de la comunicación entre familiares cuidadores y profesionales. (Chatterjee 2015, p. 281-289)

b. Beneficios específicos en función de necesidades.

\section{Arte-salud-Alzheimer y producción de conocimiento}

La intención del enfoque de este artículo hacia la institución, la mediación y la producción de conocimiento, y no exclusivamente al ámbito de la salud, pretende entender estas prácticas, no sólo desde el punto de vista terapéutico, sino como herramientas que hacen del museo una escuela y por tanto un espacio de aprendizajes transversales y útiles. 
Cuando la OMS (2006) define la salud como el estado de bienestar físico, mental y social, y no solamente la ausencia de afecciones y enfermedades, la salud deja de ser un fenómeno exclusivamente médico, para ser un problema que atañe a todos los actores sociales y el museo es uno de ellos.

Inevitablemente este nuevo enfoque de servicio y búsqueda de públicos desde el museo, está provocando diferentes encuentros en los que el contexto arte-salud ha inscrito un marco propio. En este marco los acercamientos más frecuentes son a contextos de salud mental, discapacidad funcional y cognitiva, niños hospitalizados, y mayores (Chatterjee, 2010). Colectivos, por otra parte, que muestran una gran disposición a establecer este tipo de colaboraciones y abren puertas a experimentar nuevas propuestas. No en vano sobre el bienestar y las aportaciones que la práctica artística y las instituciones culturales traen consigo a estos colectivos, existe una amplia literatura y recogida de experiencias. Buena muestra de ellas dentro del territorio español y el contexto Alzhéimer están recogidas en dos tesis doctorales recientes:

- Arte y salud: diseño e implementación de talleres y contenidos digitales de ámbito cultural para pacientes con Alzhéimer y otras demencias. López (2015).

- Arte para estimular emociones y recuerdos contra el Alzheimer: el museo como espacio de inclusión social. Delgado (2016). En ambas se recogen la mayoría de los proyectos llevados a cabo en España.

Si tenemos en cuenta que, según la Fundación Alzheimer España, el 1,75\% de la población española padece esta enfermedad y en torno a ella hay cuidadores, familiares y acompañantes, parece, cuanto menos pertinente plantearse la atención hacía este colectivo, no solo en términos de salud, también desde las preguntas, que su condición de vida como tal (la pérdida de memoria y lenguaje), pueden generar en la forma de construcción social del conocimiento y la producción cultural. Volviendo a Deligny, (Garcés, 2016 p. 12) cabe preguntarnos de qué está hecho nuestro lenguaje si lo miramos a través de aquellos que no pueden disponer de él. ¿Qué veremos entonces? ¿Qué seremos capaces de entender y expresar?

La visión de la experiencia desde estos lugares tiene un potencial que precisa atención desde múltiples direcciones. Por eso, establecer relaciones entre metodologías de intervención y prácticas del arte, la mediación y lo pedagógico, la porosidad y la intención de producción de conocimiento que se establece entre las mismas, supone ampliar las posibilidades de inclusión o como queramos denominar al hecho de construir una sociedad de no exclusión.

\section{La propuesta}

Se presentó a la terapeuta y a la asociación en una reunión a través del Patronato de Bienestar Social.

\subsection{La importancia de definir los conceptos}

Partir de conceptos bien definidos es importante a la hora de entender desde donde actuamos y cómo hacerlo para contribuir mejor a una experiencia significativa, que en definitiva es la experiencia artística. Los conceptos son herramientas muy potentes, porque nos permiten elaborar los verdaderos problemas, abrirlos y compartirlos. 
A esto no le podemos llamar salvar el mundo, pero si ponernos en la situación de entender algunos de sus aspectos y transformarlos. Garcés (2016).

El espacio expositivo y el arte contemporáneo son, a priori, lugares en los que sentirse extranjero cuando no se domina el contexto $<$ Arte $>$. La institución se percibe como órgano de conocimiento unidireccional y silenciosamente deja al espectador, no experto, en una posición de vulnerabilidad. ¿Cómo, entonces, hacer de él un lugar seguro, propicio para la interacción social, el bienestar, la creatividad y la reflexión abierta?

\subsubsection{Habitar}

La idea de habitar se presenta aquí desde dos perspectivas: como estrategia que permite un modo de estar en el museo desde la seguridad, la confianza y la creatividad. Y como concepto sobre el que trabajar la propuesta expositiva y construir un paisaje que nos permita dialogar con los otros paisajes a partir de la creación y la intervención.

En el pensamiento de Ivan Illich (1989) habitar es un arte y únicamente los seres humanos aprenden a habitar. Habitar un territorio es recorrerlo, reconocerlo, convivirlo. En este sentido participar significa vivir y relacionarse de un modo diferente. Según Heidegger (1994) para habitar hay que pensar, por eso es sólo una posibilidad de las personas.

\subsubsection{Cotidiano}

La vida cotidiana no está en lo que hacemos cada día, a eso lo podríamos denominar rutina, sino en los sentidos que esas prácticas representan. Para Javeau (2012) lo cotidiano es el lugar de la creación o la perpetuación de todos los significados definiendo la vida cotidiana a partir del recuerdo o la evocación de experiencias vividas en otro momento en un lugar cuando se vuelve a él. Afrontamos la idea de lo cotidiano también desde dos perspectivas: hacer del museo ese lugar cotidiano. Y traer lo cotidiano a la sala para crear paisajes propios que permitan habitar.

\subsubsection{La instalación como forma de habitar y producción cultural colectiva}

En qué medida construir implica habitar es otra pregunta que se hace Heidegger y que nos sirve como excusa para experimentar con la instalación artística como elemento que se construye y estrategia del habitar y la mediación. La Instalación ofrece una alternativa de solución plástica que facilita la creación colectiva, presenta la construcción de un espacio a través de diferentes elementos que permiten relacionase con quienes deciden participar en ella.

«El término «Instalación» en el lenguaje cotidiano se relaciona fundamentalmente con el acondicionamiento de algún espacio para un fin específico. De ahí que se nombra así a una instalación eléctrica, de muebles, máquinas, etcétera, en el sentido de acomodar, situar, adaptar. Pero también se emplea bajo un sentido artístico, donde los elementos dispuestos plantean una realidad propia y desde ella se invita a la construcción de nuevos saberes o experiencias dentro de este contexto: ... finalmente, toda instalación es un pequeño laboratorio donde no es real cosa alguna más allá de su funcionamiento dentro del experimento.» (Oliva, 2010. p.46). 
Construir lugares propios, en relación al espacio en el que estamos puede entenderse como un habitar, por tanto, como un acercamiento y una forma de reflexionar.

\subsection{Metodología}

El posicionamiento metodológico de la acción y el diseño del programa se fundamenta en la flexibilidad para adaptarse a la respuesta de los participantes ante las acciones propuestas, tal y como plantea Ullán (2011), dentro del proyecto AR.S: Arte y salud, en establecer como primer criterio que «el diseño de las acciones debe llevarse a cabo de manera que estas puedan formar parte de un programa preparado para personas adultas que no presenten patologías neurológicas». Este permite explotar al máximo las posibilidades de un grupo heterogéneo, generar situaciones de colaboración y provocar una mayor motivación ante el hecho de que todos se enfrentan a un reto en la medida de sus posibilidades. En base a ello podemos hablar de la metodología desde dos lugares: uno que responde más a un planteamiento conceptual y el pragmático.

\section{Conceptual}

- Generar situaciones de extrañamiento, es decir, que llamen significativamente la atención y despierten la curiosidad. Esto da lugar a que las preguntas surjan por parte de los participantes y no tanto desde la educadora. En ese sentido podemos pensar que la exposición ya es, en sí, un elemento extraño, que se puede abordar desde el discurso explicativo y la pregunta dirigida. El hecho de abordar la comprensión de la misma desde situaciones, como las que se describirán más adelante, que provocan experiencias concretas, es decir, emociones, imágenes y pensamientos, es lo que abre posibilidades. Esas posibilidades son las que, precisamente, permiten a la educadora, entrar en lo inesperado y construir desde una relación bidireccional, claro está, sin perder de vista los objetivos

- Las obras con las que trabajar deben responder al interés de los participantes, las elije el grupo y no la educadora. Esto, nuevamente, requiere acciones y estrategias que aglutinen ideas troncales que permitan ser adaptadas desde la improvisación, entendiendo por improvisación llevar una batería de recursos que nos permitan adaptarnos, aunque no siempre vayamos a utilizar.

- Realizar preguntas abiertas, que dejen lugar a la expresión y liberen al participante de la presión de tener que dar respuestas correctas o incorrectas, esto facilita el desarrollo de la creatividad y sobre todo activa la participación.

- Ni trabajos manuales, ni acciones reproductivas. Creatividad, improvisación y valoración del proceso.

- Trabajar siempre en la sala, con la presencia de las obras y afectando al espacio de la misma. Esta es una manera de no perder las referencias con las que estamos trabajando y al mismo tiempo hacer visible el proceso de producción que se lleva a cabo a partir de la propuesta expositiva. De una parte, se hace visible el grupo, sus comentarios, sus reflexiones y de otra se interviene en el espacio expositivo desde la generación de las diferentes acciones y la materialización de las mismas, que en este caso concreto será una instalación.

- Vincular las imágenes con emociones, paisajes propios y objetos. 


\section{Pragmático}

- Llevar a cabo varias sesiones que permitan el conocimiento del grupo y la progresión del mismo. Es interesante conocer al grupo previamente en su propio contexto y crear desde el principio un vínculo mutuo y una expectativa.

- La presencia de dos educadoras. Esto permite recoger más matices y poner atención desde diferentes perspectivas. Alternar el trabajo con el grupo completo y puntualmente dividir el grupo en dos. De esta manera se puede focalizar la atención sobre un aspecto concreto y permite que se produzca mayor actividad de intercambio en el grupo completo.

- Un mínimo de tres sesiones por grupo que permita apreciar la evolución del grupo y el proceso creativo.

- Crear un punto de referencia que servirá de lugar de encuentro al comienzo de cada sesión y de despedida al final de la misma.

Por último, en toda acción que se desarrolle tendremos en cuenta el decálogo de lo que NUNCA se debe hacer con un enfermo de Alzhéimer cuando trabajes con él, según la Fundación de Alzhéimer en España, que entendemos como una estrategia pedagógica en cualquier contexto de aprendizaje:

1. NUNCA discutas con el enfermo, ponte de acuerdo con él.

2. NUNCA trates de razonar, distrae su atención.

3. NUNCA le avergüences, ensálzalo.

4. NUNCA trates de darle lecciones, serénalo.

5. NUNCA le pidas que recuerde, rememórale las cosas y hechos.

6. NUNCA le digas «ya te lo dije...», repíteselo cuantas veces haga falta.

7. NUNCA le digas «ya te lo dije...», dile «haz lo que puedas».

8. NUNCA le exijas y ordenes, pregunta y enséñale.

9. NUNCA condesciendas, dale ánimos o ruégale.

10. NUNCA fuerces, refuérzale.

\subsection{Objetivos}

\section{Generales}

- Acercar la comunidad afectada por Alzheimer y a sus profesionales al arte contemporáneo y al museo.

- Proporcionar a este colectivo un espacio de socialización, bienestar y aprendizaje.

- Validar las prácticas artísticas contemporáneas como estrategias pedagógicas y productoras de conocimiento para la mediación en museos con colectivos, en concreto, con personas afectadas de Alzheimer.

\section{Específicos}

- Estimular la creatividad de las personas con Alzheimer y sus acompañantes.

- Aportar herramientas artísticas a la metodología terapéutica.

- Desarrollar conceptos abstractos como habitar 
- Vincular las imágenes con emociones, paisajes propios y objetos para producir historias.

- Emplear la fotografía, el dibujo y la instalación como herramientas de creación y desarrollo de habilidades creativas.

- Apoyar las prácticas terapéuticas y proporcionar herramientas para el mejor desarrollo de las mismas.

- Entender el espacio de la sala de arte como espacio para acción y la participación

- Valorar las posibilidades que han surgido.

\subsection{Desarrollo y metodología específica de las sesiones}

$\mathrm{N}^{\mathrm{o}}$ grupos: 2. Formados por 12 afectados en diferentes estadios de la enfermedad, 1 acompañante en el primero y 3 en el segundo.

$\mathrm{N}^{\mathrm{o}}$ sesiones: 3 por cada grupo.

Duración sesión: 1:30 h.

Mediadores: 2.

Preguntas clave: ¿Cuáles son nuestros paisajes favoritos? ¿Qué es habitar? ¿Cómo habitar un lugar que no conocemos? ¿Cómo vincularlo a nuestra historia de vida? ¿Cómo dialogar con las imágenes de paisajes habitados por otros? Y si no podemos recordar cómo habitar ¿cómo podemos activar la experiencia?

\subsubsection{Acción de presentación y situación en el espacio}

Situados en círculo comienza cualquiera empujando una bola de trapillo, con el pie, hacia alguno de los presentes. El que recibe la bola se presenta y nos habla de su paisaje favorito y por qué. Según vamos conociendo los nombres nos pegamos una etiqueta con el fin de recordarlo. En el suelo se va diseñando un dibujo en que el cada vértice responde a la ubicación de una persona. Una vez presentados todos y creado el dibujo en el suelo se lanzan una serie de preguntas acerca de la idea de paisaje: qué es el paisaje, qué entendemos por paisaje, como lo utilizamos, cómo lo habitamos. El dibujo en el suelo, en adelante $<$ paisaje propio $>$ se presenta como un lugar propio que puede cambiar y en el que se puede actuar. De esta manera surge el juego de andar entre los huecos, saltar dentro del dibujo/paisaje. Comienza la acción de habitar.

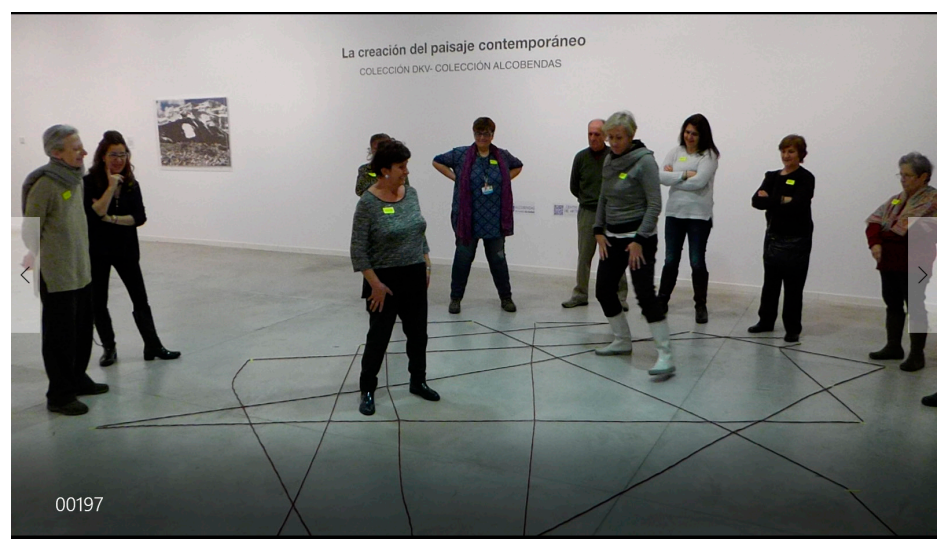

Fig. 1. Paisaje propio. (Centro de Arte Alcobendas) 
En las siguientes sesiones, ese dibujo se reproducía en el mismo lugar de la sala, se retoma el trabajo de la sesión anterior y sirve de punto de encuentro al término de la misma, donde se comenta la experiencia y se apunta lo importante para la vez siguiente.

\subsubsection{Las sesiones}

\section{Sesión 1}

Nos dividimos en dos grupos, uno con cada mediador para hacer un recorrido en busca de aquello con lo que más se identifiquen. No se da información concreta de las obras, salvo que lo pregunten. Se actúa desde la pregunta abierta que invite por un lado a la descripción objetiva y por otro a una interpretación propia vinculada a paisajes conocidos o experiencias vividas.

Orfelina identificó esta imagen con las carboneras para hacer carbón vegetal que había visto durante su niñez/juventud: «y entonces cortan la leña y hacen que esa escalera que hay puesta, por esa escalera suben la leña y la echan por arriba y van haciendo en el horno huecos con palos y cuando está el hueco van echando en trozos y luego van tapando con tierra y dejan el carbón encendido y lo cierran y así se va quemando, quemando...»

Se introduce entonces el concepto de habitar. Para finalizar cada persona se lleva una copia a color de la imagen que más le ha atraído.

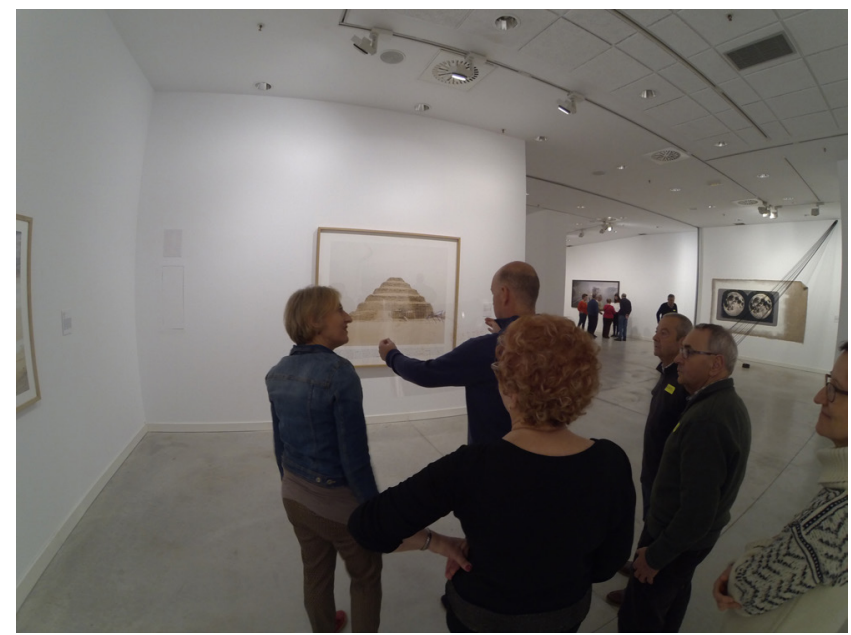

Fig. 2. Orfelina ante la imagen que inspiró el relato de la carbonera. (Centro de Arte Alcobendas)

\section{Sesión 2}

Volvemos al recorrido tras la reunión previa en el <paisaje propio>, cada grupo se centramos en las imágenes elegidas ¿Qué historias nos cuentan los paisajes, ¿cómo podemos habitarlos, ¿qué necesitamos para ello? ¿Qué memorias nos traen? 
Para poder visibilizar y recoger estas impresiones se llevan a cabo dos acciones, ambas situándonos en la sala frente a las obras:

1) Se presenta un acetato transparente tamaño $\mathrm{A} 2$ sobre una superficie rígida que permita apoyarse para dibujar y/o escribir con un rotulador permanente. Sobre este, cada participante, dibuja o escribe expresiones y palabras que afloran en la conversación.

2) Grabar lo que cuentan en base a las preguntas realizadas, con lo que van construyendo un relato.

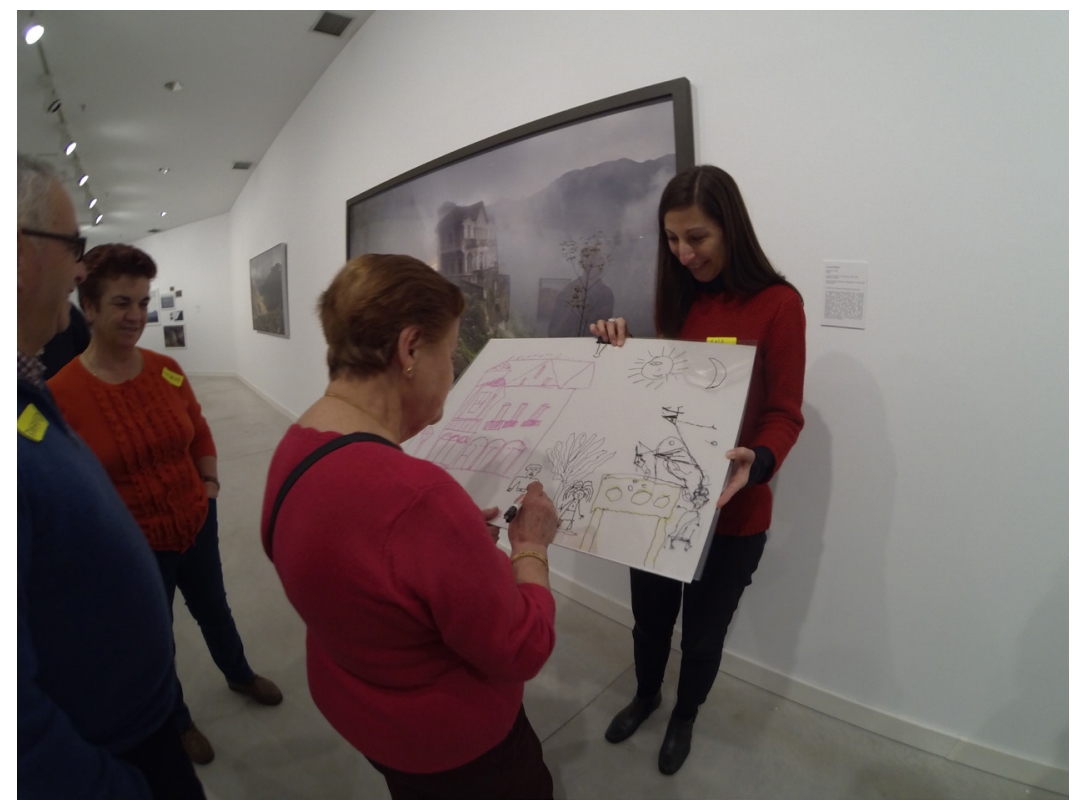

Fig. 3. Dibujando sobre el acetato frente a la obra. (Centro de Arte Alcobendas.)

Finaliza la sesión, alrededor del paisaje propio se formulan dos nuevas preguntas: ¿qué objeto llevarías a un lugar que quisieras habitar? ¿Qué objeto traerías a ese paisaje donde hemos creado historias? Y el encargo de traerlo.

\section{Sesión 3}

Destinada a llevar a cabo la intervención sobre las obras en el espacio de la sala. Cada grupo prepara la suya por separado y cuando están terminadas se la presentan unos a otros. Nuevamente se lleva a cabo el relato, esta vez hacia los compañeros.

Para aquellos que no han traído el objeto se disponen unos cubos blancos de poliexpan sobre los que puedan escribir el nombre o dibujar el objeto que hubieran traído. Es una forma simbólica de hacerlo presente. Sobre cajas de cartón grandes, a modo de pedestal, y situadas frente a la obra se colocan los objetos: mientras, dos personas sujetan el acetato sobre el que se dibujó y escribió justo delante de obra, entre esta y los objetos. Comienzan a relatar una historia de forma colectiva, en la que, a través de preguntas, cada uno va integrando su objeto en el paisaje siguiendo el relato. Cuando todo está presentado se activan las grabaciones de los relatos del día anterior en torno a la imagen y quedan integradas en la instalación. 


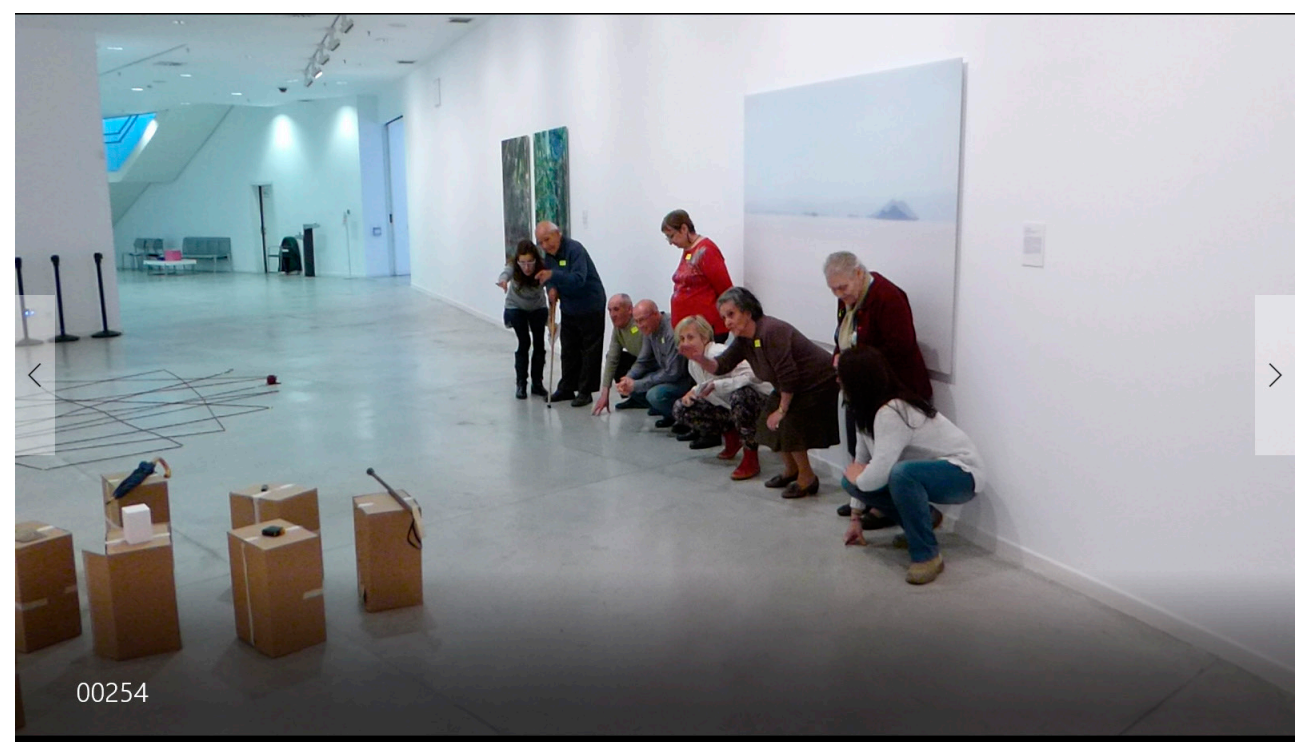

Fig. 4. Contemplando el trabajo realizado. (Centro de Arte Alcobendas.)

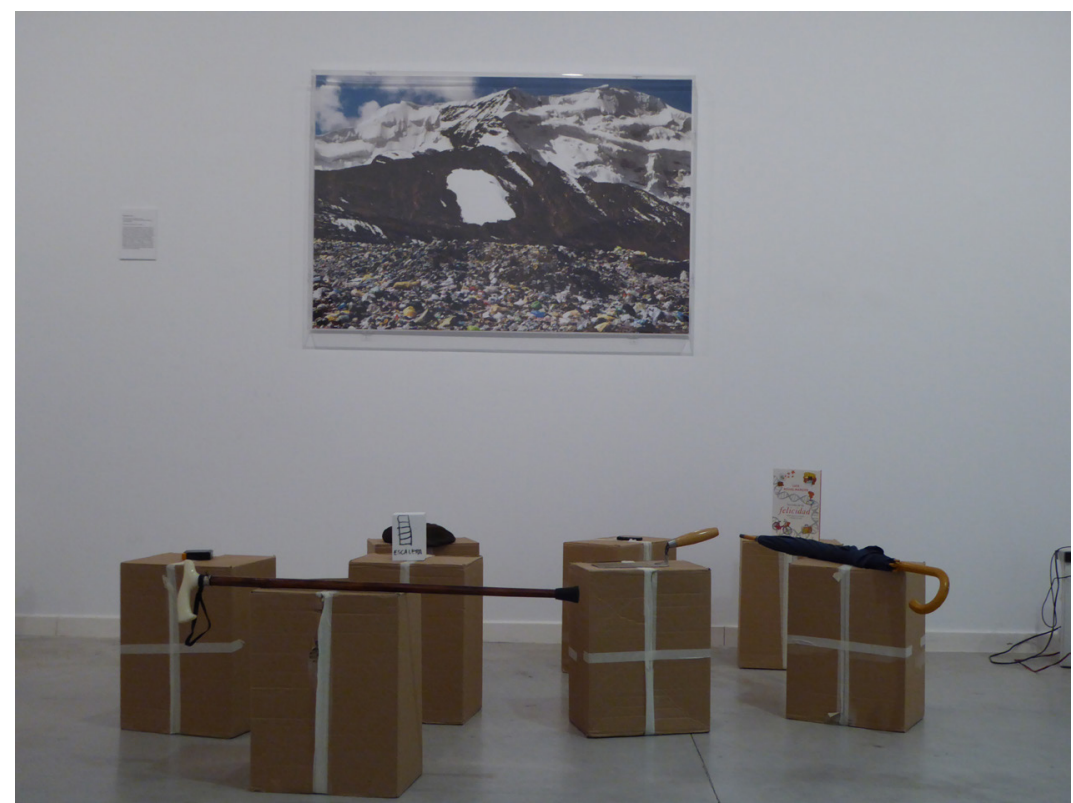

Fig. 5. Intervención en la sala frente al paisaje. (Centro de Arte Alcobendas.)

\subsubsection{Análisis de lo sucedido}

En una reunión posterior formada por dos educadores y la terapeuta, se pusieron en común los aspectos más relevantes de la experiencia en torno a preguntas que dieran respuesta a los objetivos. 
1. ¿Qué áreas de estimulación se han trabajado?

- La memoria a largo plazo desde las preguntas ¿qué te sugiere?, ¿qué te recuerda?, ¿qué añadirías?

- La memoria autobiográfica y episódica. Ambas repercuten en la autoestima.

- La atención y la concentración.

- Razonamiento a través de la insistencia en la pregunta.

- Creatividad y capacidad de asociación. Se han creado historias y narraciones vinculadas a la propia experiencia desarrollando el hilo conductor a través de preguntas. Según la terapeuta la insistencia en la pregunta es precisamente lo que les mantiene atentos. Además, lo interpretan como interés e implicación.

2. ¿Adecuación del tiempo y las sesiones?

Hora y media ha resultado escasa, los procesos son lentos, la sensación ha sido que, justo cuando se estaba en el mejor momento de la actividad, había que cortar. A pesar de estar de pie durante toda la sesión, nadie manifestó cansancio. Posiblemente el hecho de estar concentrados y atentos les distrae de ese hecho. Para la terapeuta ampliar el tiempo de cada sesión sería recomendable.

Se considera interesante incluir alguna sesión más que pueda contribuir a llevar a cabo un trabajo estético más impactante aún, por un lado, y por otro que les permita desarrollar su confianza en el espacio y soltura en la acción mostrada especialmente en la tercera sesión.

3. ¿Diferencias entre el primer grupo y el segundo?

Funcionó mejor el segundo por cuestiones circunstanciales que dejaron aflorar la importancia de la presencia de la terapeuta. Durante el trabajo con el primer grupo la psicóloga no pudo estar presente, esto impidió que, durante las sesiones en su centro habitual, realizaran el trabajo que se les sugería tras nuestra sesión. En el caso del segundo grupo si se produjo.

Otro factor fue la presencia de más acompañantes.

4. El espacio del museo y el habitar.

Se valora de forma muy positiva el hecho de haber trabajado todo el tiempo en la sala, utilizar otra sala supondría una reproducción del modelo en el que ellos funcionan en sus terapias habituales. El nivel de confianza, bienestar y socialización se reveló en varias anécdotas, todas ellas acontecidas en la última sesión. La más destacable se produjo en el primer grupo: aunque no todos, muchos de ellos trajeron los objetos que se habían acordado en la sesión anterior, parte de esos objetos eran una mesa, sillas y platos donde comer. Una acompañante trajo pastas y cuando volvimos a reunirnos en el punto de encuentro, las abrió con toda naturalidad y pasamos un rato de charla comiendo pastas en el museo.

6. ¿Cuáles han sido las acciones más valoradas?

- La intervención sobre los acetatos, en la que a pesar de las dificultades para el dibujo y la escritura habían intervenido todos con buena disposición. 
- La escucha de las grabaciones de sus relatos y la expresión de sorpresa al reconocer sus voces.

- La dinámica del paisaje propio que les ayudaba a centrarse y sentirse seguros.

- El uso de elementos que contribuyen a una experiencia estética y creativa, a la vez que no presentan dificultades técnicas que puedan resultar frustrantes en una experiencia colectiva.

- Los acompañantes más controladores se relajaron.

7. ¿Cuáles han sido las aportaciones y que posibilidades surgen?

Frente a la forma habitual de trabajo muy estructurada y centrada en determinados contenidos, la experiencia ha aportado una forma de trabajar en la que contemplar las competencias de la terapia de una manera más libre, lo que permite un enfoque más flexible y relajado ¿divertido? para todos y por tanto menos cansado. Se ha incorporado el trabajo con la fotografía de paisajes para llevar a cabo alguna de las actividades que anteriormente se desarrollaban con fichas. En palabras de Estela «la ficha no deja de ser un elemento que te limita mucho».

Dentro de este apartado es interesante también contestar a las preguntas que proponíamos en el apartado 3. investigar de manera que puedan ayudarnos a establecer un análisis que se acerque también a la valoración de acciones que queremos considerar transformadoras y valiosas en lo social.

\section{¿Qué encontramos al principio?}

Un grupo dispuesto, pero tímido, con acompañantes que actúan desde el cuidado y la protección, que se adentran juntos por primera vez a una experiencia frente al Arte Contemporáneo.

Una psicóloga que se enfrenta a la experiencia, también desde la novedad, pero con visión observadora y participante.

\section{¿Qué tenemos al final?}

Una reunión de amigos que se sienten a gusto y motivados, que han generado historias, manejado materiales, reflexionado sobre conceptos como habitar y conectado con experiencias de vida y recuerdos.

Unos acompañantes liberados de su carga protectora e incorporados de forma autónoma al tiempo que han cedido autonomía a los afectados.

\section{¿Para quién es útil y desde qué perspectiva?}

Para los afectados, tal y como se ha expuesto en el apartado anterior se ha desarrollado todo un trabajo relacionado con lo terapéutico.

Para la terapeuta ha sido una experiencia de observación desde otra perspectiva que le ha permitido tomar herramientas para su trabajo en el centro e incorporar estrategias e imágenes empleadas en los talleres a su propio trabajo.

Para el museo una experiencia de conexión con el tejido del barrio, una forma de visibilizar otros públicos y ponerse a disposición de la comunidad. Un reconocimiento de la necesidad de profesionales que puedan dirigir estas experiencias. El 
propio Centro de Arte propuso continuar durante el curso 2017/2018 las actuaciones con colectivos arte-salud.

\section{¿Es posible un cambio sostenible?}

Posible si, difícil también a pesar de que la experiencia es positiva y se valoran cuestiones relevantes incorporar nuevos hábitos a las dinámicas cotidianas de las terapias resulta difícil. El trabajo en este sentido resulta un esfuerzo para el museo que debe poner no sólo recursos, también empeño y constancia. Las experiencias aisladas funcionan, pero es necesaria la continuidad en la propuesta de relación a los diferentes colectivos.

\section{¿Qué conocimiento se produce?}

En principio, basándonos en los hechos y lo expuesto en las evaluaciones se produce un conocimiento útil, en cuanto a la incorporación de otras posibilidades que pueden calificarse de mejoras en las metodologías terapéuticas habituales. Aprendizajes útiles en cuanto a cómo el grupo se acerca al espacio del arte desde la familiaridad. Pero también se produce un conocimiento pedagógico, en cuanto que ello significa poner en marcha experiencias (tentativas) y evaluar procesos de aprendizaje aprovechando las aportaciones multidisciplinares como el arte, la educación, la psicología en este caso con el fin de favorecer al máximo el desarrollo de las personas y las sociedades

\section{Conclusiones}

En términos generales y en base a las respuestas de la terapeuta a las preguntas realizadas, la propuesta ha funcionado y ha alcanzado los objetivos propuestos, tanto los generales como los específicos.

Como conclusión más significativa tomaremos la respuesta de la terapeuta a la última pregunta, en la que se pone de manifiesto una cuestión que, a priori, no se había tenido en cuenta. Si bien sí se planteaba dentro de los objetivos proporcionar herramientas a la terapia, no se ha hecho tanto desde haber detectado, lo que para la terapeuta parece una evidencia: la necesidad de salir de la estructura cerrada y poco flexible de las terapias habituales. Evidencia que lleva a valorar de forma muy positiva el aprendizaje de otras estrategias y herramientas que permitan una mayor flexibilidad y por tanto contribuyan a una menor fatiga y un mayor disfrute para todos.

Este «para todos» resulta especialmente relevante puesto que supone, por un lado la necesidad de seguir investigando desde estas prácticas e ir valorando aportaciones que no sólo contribuyan al bienestar de los afectados, sino que hagan aportaciones significativas a los procesos terapéuticos detectando necesidades de los mismo. Por otro entender al colectivo Alzheimer como un grupo de personas más allá de los afectados directamente. De manera que, cara al planteamiento sobre el museo y la sala de arte como lugares para la creación de conocimiento bidireccional, el servicio a la comunidad y la contribución a la transformación social, y a las prácticas artísticas contemporáneas se produce 
otra mirada más allá del estricto ámbito de «salud» tal y como se ha venido entendiendo hasta ahora.

Frente a muchas de las actuaciones educativas revisadas en el contexto de salas de arte y museos, la experiencia descrita presenta una serie de diferencias comparables, que aportan un nuevo modelo de mediación caracterizado por desarrollarse en el propio espacio de la sala, desarrollar un diseño universal con acciones posibles para grupos heterogéneos con roles y capacidades diferentes que adquieren aprendizajes diferentes y por último, una cuestión sobre la que no se ha insistido en esta ocasión, pero que resulta importante: el uso de materiales cotidianos que no requieren destreza en su manipulación pero que sean de carácter simbólico, ya que ello facilitado la expresión del proceso artístico sin la frustración que supone pretender trabajar estéticas que requieren grandes habilidades técnicas.

\section{Discusión}

Queda por ver cómo podemos evaluar la experiencia más allá de las evidencias arrojadas según la terapeuta. Qué hay en ella que la haga funcionar de prototipo como experiencia significativa capaz de contribuir a la inclusión de las prácticas artísticas en el tejido social, y el trabajo conjunto entre el museo y los colectivos de salud. Qué tipo de conocimiento se genera cara a la transformación de las relaciones entre el museo y los colectivos y por tanto cara a encontrar nuevas formas de aprendizaje y acción social, que en definitiva se traducen en salud, en su más amplio sentido.

La respuesta a estas cuestiones tan extensas, cuando estamos hablando de una experiencia puntual, más que a conclusiones nos lleva a una propuesta de continuidad. Si las valoraciones son positivas y se han establecido con criterios adecuados para todos. Si ha permitido detectar necesidades y aportar mejoras, si permiten ver a la comunidad en toda su amplitud y no sólo focalizarla en «los afectados», si se han producido experiencias significativas y creativas que por una parte contribuyen al bienestar y por otra aprendizaje metodológico y acercamiento al arte, podemos hacerlas funcionar como prototipos y no tanto como modelos y sumar conocimiento transferible. Ello requiere sin duda, una intensa labor por parte de la institución arte en emprender proyectos de colaboración con estos colectivos en los que puedan producirse situaciones tan cotidianas que conviertan el museo o la sala de arte en un espacio habitual de nuestro aprendizaje y nuestro bienestar.

\section{¿Quiénes, en un museo, comen tranquilamente pastas, si no es porque han acudido a un acontecimiento significativo y no a una simple visita?}

A continuación, se aportan algunos de los diálogos producidos a lo largo de las sesiones. Están reproducidos con la mayor fidelidad posible, precisamente, para poder apreciar el resultado creativo.

\section{Diálogo 1.}

Mediador: ¿Qué hemos traído a nuestro paisaje?

Orfelina: Aquello es un horno para hacer el carbón, que hace el carbonero. 
M: Pero ¿qué has traído?

Orfelina: porque ahí hay personas que habitan y duermen. He traído una silla,

M: ¿Quién ha traído una botella de wiski?

J.A.: Yo.

M: $\quad$ ¿Por qué?

J.A.: $\quad$ Porque me gusta (risas) y si tengo que subir hasta allí, pues voy dándole, en vez agua.

M: $\quad$ Y cuando llegues ¿qué vas a hacer?

J.A.: $\quad$ Pues llego y hago lo otro por abajo.

Ed. ¿YY no vas a invitar a Orfelina a un poco de wiski?

J.A.: $\quad$ NO. Porque el wiski me lo voy a beber yo. (más risas)

\section{Diálogo 2}

M: $\quad$ Juanjo ¿qué has puesto en este paisaje?

J: $\quad$ La piedra.

M: ¿Y por qué?

J: $\quad$ Por tenerla simplemente.

M: $\quad$ ¿Qué has hecho con la piedra?

J: $\quad$ La habré manchado. Pintarla para que quede más bonita.

M: $\quad$ Y tu Santos ¿qué has traído?

S: $\quad$ Yo, Nada. Las manos, para poder hacer lo que tengamos que hacer.

M: $\quad$ ¿En qué se ha convertido este paisaje?

Inma: $\quad$ En una reunión de amigos

Carmen: Porque nos hemos juntado todos y estamos todos muy a gusto.

M: $\quad$ ¿Le ponemos fin a la historia?

I: $\quad$ Yo creo que sí. Yo por lo menos estoy a gusto e imagino que los demás también.

\section{Diálogo 3}

X: Había una vez una casa solitaria en mitad del campo y una pareja se estaba peleando porque el marido no le ayudaba a colgar las cortinas.

M: Inma, ¿cómo seguirías eso?

I: El marido no quería, pero le convencí para que colgara las cortinas. Porque era necesario, para que no te vea nadie desde fuera.

El marido contesta a Inma: Y di que soy muy obediente.

I: y eso, es obediente.

M.: y el martillo ¿cómo lo meterías en la historia?

J.: El martillo para colgar las cortinas.

J.A.: Se rompe una mesa y hay que arreglarla e hice una mesa para comer.

M: ¿Qué más podemos poner en la mesa?

J.A.: Una tele para ver las noticias, las pelis, cualquier cosa.

«Así como pienso que es ilusorio apostar a una transformación de la sociedad, también creo que las tentativas microscópicas, como las experiencias comunita- 
rias, las organizaciones barriales, la implantación de una guardería en la universidad, etc., juegan un papel absolutamente fundamental»

Guattari (Borriaud 2006 p.35)

\section{Referencias bibliograficas}

Borriaud, N. (2009). Estética Relacional. Buenos Aires. Argentina. Adriana Hidalgo

Chatterjee, HJ.(2015) Museums and art Galleries in public healthArts. and public health in different setting. Cap. 34 en Oxford Textbook of Creative Arts, Health, and Wellbeing International perspectives on practice, policy and research. Clift, S. y Camic, P. (ed.)

Deleuze, G. y Guattari, F. (2005) Rizoma. Valencia. España.: Pretextos

Delgado, M. (2016) Arte para estimular emociones y recuerdos contra el Alzheimer: el museo como espacio de inclusión social. Tesis doctoral. Universidad Complutense de Madrid.

Deway, J. (2008) El arte como experiencia. Paidós. Barcelona.

Garcés, M. (2016) Fuera de clase. Textos de filosofía de guerrilla. Barcelona. España.: Galaxia Gutemberg, S.L.

G. Cano, M. (junio de 2014). Arte contexto y participación. Los espacios de salud como espacios artísticos y el arte como investigación. II Congreso internacional de Arte y Salud. DKV. Denia. Valencia.

G. Cano, M. (2013) Arte, contexto y participación: el hospital como espacio artístico. (tesis doctoral) Universidad Complutense de Madrid, España.

Heidegger (construir, habitar, pensar. Conferencia Recuperado (10-2017) de https://jcmansur. wordpress.com/estetica-y-ciudad/conferencia-de-heidegger-construir-pensar-habitarbauen-denken-wohnen/

Illich, I. (1989). La reivindicación de la casa. Alternativas II. México: Joaquín Mortiz/ Planeta.

Javeau, C. (2012). Ocho proposiciones sobre lo cotidiano. Recuperado (9-2017) de

http://cmap.javeriana.edu.co/servlet/SBReadResourceServlet?rid=1332521673227_258249675_3133

Méndez, L. (2015). Arte y salud: diseño e implementación de talleres y contenidos digitales de ámbito cultural para pacientes con Alzhéimer y otras demencias. Tesis doctoral. Universidad Complutense de Madrid.

Morales, E. (2015). Nuevos formatos educativos para la comunidad en centros de arte [Manuscrito] : de los talleres de familia a los talleres intergeneracionales: un estudio de caso en Matadero-Madrid. (Tesis Doctoral) Universidad Complutense de Madrid.

Mörsch, C. (2010). At a Crossroads of Four Discourses: documenta 12 Gallery Education in Between Affirmation, Reproduction, Deconstruction and Transformation. En Mörsch et al. (ed.), Documenta 12 education\#2: Between Critical Practice and Visitor Service. (pp.931) Berlin and Zürich: Diaphanes.

Oliva, C. (2010). El fin del Arte, México D.F.: Ítaca.

OMS (Organización Mundial de la Salud) (2006). Constitución de la organización mundial de la salud. Recuperado (10-2017)de http://www.who.int/governance/eb/who_constitution_ sp.pdf?ua $=1$ 
Pedagogías y redes instituyentes. (2013).Mediación y educación en museos/centros de arte. Recuperado (10-2017) https://redesinstituyentes.wordpress.com/glosario-y-referentes/ mediacion-y-educacion-en-museos-centros-de-arte/

Parramón, R. (2003). Arte, participación y espacio público. Jornadas de Innovación estratégica 15/10/2003.

Rodrigo, J. (2012). Los museos como espacios de mediación: políticas culturales , estructuras y condiciones para la colaboración sostenible en contextos Recuperado de $\mathrm{h}$ ttp://www. kultur-vermittlung.ch/zeit-fuer-vermittlung/download/materialpool/MFV0107.pdf. $2 / 11 / 2016$.

SEC (Secretaría de Estado de Cultura de España) (2015). Plan Museos + Sociales. Recuperado (8-2017) de: http://www.mecd.gob.es/dms/microsites/cultura/museos/museosmassociales/ presentacion/plan-museos-soc.pdf

Ullán, A. M. (2011). Una experiencia de educación artística contemporánea para personas con demencia. El Proyecto AR.S: arte y salud. Arte, Individuo y Sociedad, 23 Núm. especial, (p. 77-88.) Universidad Complutense de Madrid.

\section{Webs}

Centro de Arte Alcobendas. http://www.centrodeartealcobendas.org/

Asociación de familiares y enfermos de Alzheimer de Alcobendas y San Sebastián de lo Reyes. http://participa.alcobendas.org/index_web.php?idwc=czo2OiJhZmFlYWEiOw==

\section{Fundación Alzheimer España.}

http://familia.alzfae.org/hay-800-000-personas-con-demencia-en-espana-o-400-000/ 